\title{
BMJ Open Health literacy issues in the care of Chinese American immigrants with diabetes: a qualitative study
}

\author{
Angela Yee Man Leung, ${ }^{1,2} \mathrm{Ai} \mathrm{Bo,}{ }^{3} \mathrm{Hsin}-\mathrm{Yi} \mathrm{Hsiao},{ }^{3}$ Song Song Wang, ${ }^{3}$ Iris $\mathrm{Chi}^{3}$
}

To cite: Leung AYM, Bo A, Hsiao H-Y, et al. Health literacy issues in the care of Chinese American immigrants with diabetes: a qualitative study. BMJ Open 2014;4:e005294. doi:10.1136/bmjopen-2014005294

- Prepublication history for this paper is available online. To view these files please visit the journal online (http://dx.doi.org/10.1136/ bmjopen-2014-005294).

Received 19 March 2014 Revised 20 October 2014 Accepted 24 October 2014

CrossMark

${ }^{1}$ Li Ka Shing Faculty of Medicine, School of Nursing, University of Hong Kong, Hong Kong, Hong Kong ${ }^{2}$ Li Ka Shing Faculty of Medicine, Research Centre on Heart, Brain, Hormone and Healthy Aging, University of Hong Kong, Hong Kong, Hong Kong

${ }^{3}$ School of Social Work, University of Southern California, Los Angeles, California, USA

Correspondence to

Dr Iris Chi;

ichi@usc.edu

\section{ABSTRACT}

Objectives: To investigate why first-generation Chinese immigrants with diabetes have difficulty obtaining, processing and understanding diabetes related information despite the existence of translated materials and translators.

Design: This qualitative study employed purposive sampling. Six focus groups and two individual interviews were conducted. Each group discussion lasted approximately 90 min and was guided by semistructured and open-ended questions.

Setting: Data were collected in two community health centres and one elderly retirement village in Los Angeles, California.

Participants: 29 Chinese immigrants aged $\geq 45$ years and diagnosed with type 2 diabetes for at least 1 year.

Results: Eight key themes were found to potentially affect Chinese immigrants' capacity to obtain, communicate, process and understand diabetes related health information and consequently alter their decision making in self-care. Among the themes, three major categories emerged: cultural factors, structural barriers, and personal barriers.

Conclusions: Findings highlight the importance of cultural sensitivity when working with first-generation Chinese immigrants with diabetes. Implications for health professionals, local community centres and other potential service providers are discussed.

\section{INTRODUCTION}

Diabetes is a chronic illness that affects many Americans, particularly ethic minority populations. For more than a decade, ethnic minority populations have had a higher prevalence of diabetes than the White population. ${ }^{1}$ A recent study using data from the National Health Interview Survey from 1997 to 2008 showed that after adjusting for age, sex, body mass index, income and reported exercise levels, Asian Americans are approximately $30 \%$ more likely to have type 2 diabetes than their White counterparts, a trend that has remained quite stable during the previous decade. ${ }^{2}$ Using data from the 2009 California Health Interview Survey, one study

\section{Strengths and limitations of this study}

- The use of qualitative methods provided opportunities to explore possible reasons why Chinese immigrants had difficulty obtaining, communicating, processing and understanding diabetes related information.

- This is the first study of cultural influences on individuals' health literacy in an immigrant population.

- The study had limitations in sampling; the findings therefore cannot be generalised to all Chinese Americans with type 2 diabetes.

found that older Asian Americans with diabetes are less likely than their White counterparts to test their blood glucose regularly or have a foot examination. ${ }^{3}$ Among Asian Americans, Chinese Americans represent the largest subgroup $(23.8 \%)$ and have a high prevalence of undiagnosed diabetes (11.4\%) compared to the national average $(3.8 \%){ }^{4}$

Chinese American immigrants encounter challenges in diabetes care in many ways, including limited health literacy. Health literacy is defined as the degree to which an individual has the capacity to obtain, communicate, process and understand basic health information and services to make appropriate health decisions. ${ }^{5}$ A graphical presentation of the definition of health literacy is shown in figure 1. The four components of health literacy (HL), namely obtaining health information and services (HL1), communicating with others about their needs and preferences and responding to the received information (HL2), processing the meaning and usefulness of the information and services (HL3), and understanding the choices, consequences and context of the information and services (HL4), are illustrated in the figure. This definition of health literacy echoes the argument that oral communication skills are considered a critical component of health literacy. ${ }^{6}$ These 
Figure 1 Health literacy, as defined by the Centers for Disease Control and Prevention, comprises four components. On obtaining health information and communicating with others, an individual would process the meaning of the information and understand the choices or consequences before making a decision. However, due to the complexity of information on different occasions, an individual may not employ all four components of health literacy at one time (or in the same sequence as illustrated) before making a decision.

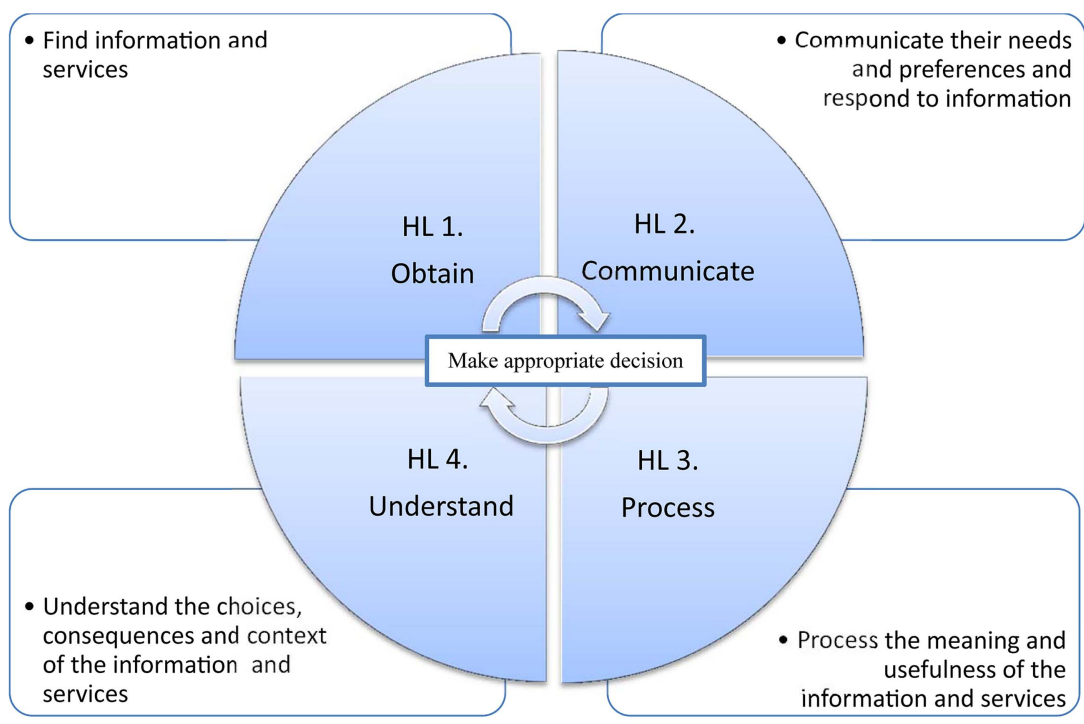

Note. $\mathrm{HL}=$ health literacy components of health literacy assist individuals in making appropriate and informed health decisions (ie, individuals make such decisions based on the information they obtain, communicate with others, process and understand). ${ }^{6}$ Because the quantity and complexity of information may be different for different health decisions, individuals may not employ all four components of health literacy at one time or in the same sequence as illustrated in figure 1.

To show the connection between the definition of health literacy and the discussion in this paper, we use abbreviations (eg, HL1, HL2, etc.) to indicate which components of health literacy we are referring to when we describe the idea of health literacy in the subsequent paragraphs.

The inability to obtain and understand health information is not solely related to language barriers. Many of the existing educational materials (such as pamphlets, educational CDs or videos) are translated into Chinese, and yet many Chinese immigrants do not read or cannot access these materials. A recent survey showed that only $18 \%$ of Chinese patients obtained diabetes related information from pamphlets, educational CDs or videos, whereas $53 \%$ of their English-speaking White counterparts had such access (HL1). ${ }^{7}$ Although English-Chinese translators are available in federally funded or free clinics, Chinese patients, compared with English-speaking White patients, are less likely to obtain diabetes related information from professionals (such as physicians, endocrinologists or diabetes educators; HL1 and HL3). ${ }^{7}$ Such phenomena illustrate that diabetes related information has not been transmitted to Chinese immigrants through professional communication networks, as expected. ${ }^{8}$ Little is known about the reasons why diabetes related information is not accessible to Chinese patients despite the existence of Chinese translated materials and translators and why the information cannot be processed and understood by Chinese patients.

Chinese Americans also struggle with conflicts between health related information from professionals and cultural beliefs. ${ }^{49}$ Chinese perceive rice as the most crucial source of energy. ${ }^{9}$ On receiving dietary advice regarding the reduction of rice consumption to control diabetes, Chinese patients considered such advice as infeasible and nearly impossible to implement. ${ }^{9}$ Thus, in this instance, dietary advice clashes with Chinese cultural norms, and Chinese Americans often choose to neglect this diet related information. ${ }^{9}$ In a survey of Chinese Americans with diabetes (aged 25-70), only 54\% reported receiving disease management advice, and those who had higher incomes and spoke English received more advice. ${ }^{10}$ It was uncertain whether advice had been offered to but not received or retained by participants, and there seemed to be a significant gap between information offered and what was received and interpreted by these participants. Therefore, it is pertinent to investigate factors that affect the ability of this population to obtain health information (HL1), interpret health messages (HL3 and HL4) and make decisions regarding health behaviours.

Despite the significance of health literacy for adult Chinese immigrants with type 2 diabetes, few studies have examined specific factors in the social context affecting health literacy in this population. Most existing studies focused on either language barriers or food beliefs and did not recognise or acknowledge other cultural and structural factors. This study was designed to address the gaps in the existing literature by conducting an in-depth qualitative exploration of the possible reasons why first-generation Chinese immigrants with diabetes had difficulty obtaining, processing and understanding health information and communicating with others about their needs and preferences. We selected 
first-generation Chinese American immigrants as the target population because they share many common characteristics with other Asian groups (such as Thai or Vietnamese) whose first language is not English and whose culture is collectivist in nature.

\section{METHODS}

\section{Participant recruitment}

Participants were recruited through purposive sampling. Participants were eligible if they were: (1) firstgeneration Chinese immigrants living in Los Angeles County, (2) aged $\geq 45$ years, and (3) diagnosed with type 2 diabetes for at least 1 year. Recruitment was conducted in regions highly populated by Chinese residents, such as Monterey Park, Alhambra and San Gabriel, through a partnership with three collaborative agencies. Recruitment strategies included posting flyers at partner agencies, making phone calls to current patients with diabetes and in-person contact. All participants were screened by brief phone or in-person interviews to assess their eligibility for participating in the study.

\section{Data collection}

Focus group moderators distributed an information sheet about the study and explained the purpose and process of the study to all participants before obtaining their written consent. Twenty-seven participants with diabetes were assigned to six focus groups with two to seven participants in each group, and two participants completed individual interviews based on their availability. Focus groups were conducted by four trained native Chinese moderators in Cantonese or Mandarin Chinese based on the participants' language preferences. One of the study investigators participated in all group discussions and interviews as the facilitator. Each discussion lasted approximately $90 \mathrm{~min}$ and was guided by semistructured and open-ended questions (as shown in box 1). Two individual interviews lasted approximately $60 \mathrm{~min}$ and were conducted by a trained native Mandarin Chinese speaker using the same interview guide used for the focus groups. Interviews were audio recorded. This study was conducted collaboratively by University of Southern California, Golden Age Village, Herald Christian Health Center and Tzu Chi Health Centre in Los Angeles, and the University of Hong Kong, Hong Kong Special Administration Region, China. Ethical approval was obtained from the Ethical Review Board of the University of Hong Kong/Hospital Authority Hong Kong West Cluster.

\section{Data analysis}

Taped discussions and interviews were transcribed into Mandarin to produce source documents for analysis in 2013. The research team conducted thematic content analysis after developing a coding scheme. Transcripts were coded by one member of the research team. The coding was cross-checked by another member of the research team. ${ }^{11}$ Cross-checking of coding and identification of themes took place during research team meetings and via email. ${ }^{11}$ Differences were discussed until all team members agreed on the most suitable interpretation. This ensured that the complexity of experiences was reflected in the analysis. Cumulative analysis can be attentive to the depth and variation of the information gathered as information from one interview or focus group influences those that follow. ${ }^{12}$ Transcripts related to key themes were translated into English by native Mandarin and Cantonese speakers who are also proficient in English. The investigators, who are also native Chinese speakers and proficient in English, checked the

\section{Box 1 Guiding questions for focus group interviews}

\section{Channels}

1. When you were diagnosed with diabetes, where did you get the information about diabetic self-management? In the future, where you would like to get such information?

2. We have collected some samples like educational brochures, storybook, and audio recorder. Which method do you think is the most effective method? Which is the least effective one? Why?

3. There is a lot of information about diabetes on the Internet or with mobile applications. Have you ever read this? If yes, what is your opinion?

4. Have you ever attended any health talk organised by health care professionals? Do you think these are effective? Why?

5. Is there any other method that we have not mentioned but you think is effective?

Styles

6. When you learn diabetic care, would you like to learn it as a group or by yourself? Why?

7. Which method suits you most: (A) lecturing from a teacher or (B) learning through activities? Why?

8. What would you think if a doctor or a nurse calls you by phone regularly, reminding you how to care for yourself? How frequent would you consider as appropriate (eg, how many weeks for each call)?

9. What would you think if a doctor or a nurse sent you SMS regularly, reminding you how to care for yourself? How frequent would you consider as appropriate (eg, how many weeks for each SMS)?

Contents

10. When you had just been diagnosed, what kind of information did you really want to get? (For example, what is diabetes? What food can I take? What food I cannot take? If I cannot control diabetes well, what would be the consequence? How to control diabetes better? Other than drugs, what other method(s) is/are effective to control diabetes? If I have insulin injection, does this mean my condition is getting worse? Should I tell my family/friends that I have diabetes? How to tell them?)

11. Having been diagnosed for some years, what do you want to learn most?

12. You have probably heard about some methods to control diabetes. Which one(s) is/are considered as unreasonable or impractical? What is/are this/these method(s)? Why? 
grammar and accuracy of the translation of the cited quotations.

We adopted a systematic approach to: (1) extract key ideas to identify the properties and dimensions of emerging concepts; (2) review and reorganise the transcriptions for individual accounts suitable for thematic analysis; and (3) identify idioms, patterns, categories and themes to provide a cognitive map of the concerns, beliefs and behaviours of study participants. ${ }^{13}$ The research team discussed the opinions and feelings of participants, with particular attention to potential ethnocultural biases.

\section{RESULTS}

\section{Sample characteristics}

Table 1 displays the demographic characteristics of the 29 participants. Sixty-two per cent of the participants were men, and the mean age of all participants was 63.6 years $(\mathrm{SD}=12.2)$. The majority of participants $(69 \%)$ were married and $42 \%$ reporting having received at least a high school education. Years since immigration ranged

\begin{tabular}{|c|c|c|}
\hline Variable & $\mathbf{n}$ & $\%$ \\
\hline Age (mean, SD) & 63.6 & 12.2 \\
\hline \multicolumn{3}{|l|}{ Gender } \\
\hline Male & 18 & 62 \\
\hline Female & 11 & 38 \\
\hline \multicolumn{3}{|l|}{ Marital status } \\
\hline Married & 20 & 69 \\
\hline Divorced or separated & 5 & 17 \\
\hline Widowed & 3 & 10 \\
\hline Unmarried & 1 & 3 \\
\hline \multicolumn{3}{|l|}{ Education } \\
\hline Grade 6 or less & 4 & 14 \\
\hline Grade $7-12$ & 13 & 45 \\
\hline No degree & 4 & 14 \\
\hline Degree & 8 & 28 \\
\hline \multicolumn{3}{|l|}{ Employment status } \\
\hline Retired & 12 & 41 \\
\hline Part-time & 9 & 31 \\
\hline Full-time & 6 & 21 \\
\hline Homemaker & 2 & 7 \\
\hline \multicolumn{3}{|c|}{ Years with diagnosed diabetes } \\
\hline $1-5$ & 10 & 34 \\
\hline $6-10$ & 10 & 34 \\
\hline $11-15$ & 4 & 14 \\
\hline$>15$ & 5 & 17 \\
\hline \multicolumn{3}{|l|}{ Preferred language } \\
\hline Putonghua (Mandarin) & 18 & 62 \\
\hline Cantonese & 11 & 38 \\
\hline \multicolumn{3}{|l|}{ Self-rated health } \\
\hline Bad & 4 & 14 \\
\hline Fair & 14 & 48 \\
\hline Good & 7 & 24 \\
\hline Very good & 4 & 14 \\
\hline
\end{tabular}

from 6 to 39, with an average of 15 years. Fewer than half of the participants were retired, approximately $30 \%$ had a part-time job and $20 \%$ had a full-time job. About one third of all participants had been diagnosed with diabetes for 1-5 years, another third had been diagnosed with diabetes for 6-10 years and the rest had been diagnosed for 11 years or more. All participants indicated that either Cantonese or Putonghua (Mandarin) was their preferred language that was commonly used at home. Approximately two thirds of participants spoke Mandarin Chinese and the other third spoke Cantonese. Most of the participants reported having fair, good or very good health; only slightly more than $10 \%$ considered themselves as being in poor health. Almost all the participants did not speak or spoke very little English.

\section{Identified themes}

Eight key themes were found to potentially affect different components of health literacy among Chinese immigrants with diabetes: cultural factors (three themes), structural barriers (three themes), and personal barriers (two themes; table 2). Three cultural factors, namely high regard for authority, a desire to avoid being burdensome to others, and a desire to be together or follow a collective approach, were identified. Beliefs or perceptions among participants seemed consistent across interviews and were grounded in Chinese culture. ${ }^{14}$ Structural barriers, such as insurance, transportation issues and limited information in Chinese-speaking communities, were identified. These structural barriers did not seem to provide a favourable environment for Chinese immigrants to obtain health information (HL1) and communicate with information providers (HL2). When processing the information, Chinese immigrants said they found it hard to apply it to daily practices (HL3). Personal factors, namely unawareness of self-care responsibility and age related limitations, might affect their capacity to obtain health information (HL1) and communicate with others (HL2). Below are detailed descriptions of the eight themes.

\section{High regard for authority}

A positive attitude towards authority was the most common characteristic among all participants. Almost all participants reported that they preferred to receive health education information directly from doctors. Physicians were viewed as highly respected figures. Most participants felt reluctant or uncomfortable about confronting or engaging with their physicians when they could not understand or follow their instructions. They even felt unwilling to discuss their treatment plan with their physicians because they believed that whatever physicians said was right and patients should always obey their physicians. On some occasions, they admitted they could not openly communicate with their physicians due to unwillingness to challenge their authority. 
Table 2 Meanings and interpretations of key themes

\begin{tabular}{|c|c|}
\hline Themes & Meanings and interpretations \\
\hline \multicolumn{2}{|l|}{ Cultural factors } \\
\hline High regard for authority & $\begin{array}{l}\text { View physicians as authoritative figures, like fathers } \\
\text { Reluctant to confront physicians }\end{array}$ \\
\hline $\begin{array}{l}\text { A desire to avoid being burdensome to } \\
\text { others }\end{array}$ & $\begin{array}{l}\text { Feel health professionals and family members have made significant efforts to } \\
\text { offer help, services and support to patients with diabetes } \\
\text { Do not expect doctors or nurses to organise patient support groups } \\
\text { Feel dietary restrictions should not be mentioned to avoid others from being } \\
\text { influenced }\end{array}$ \\
\hline $\begin{array}{l}\text { A desire to be together or follow a } \\
\text { collective approach } \\
\text { Structural barriers }\end{array}$ & $\begin{array}{l}\text { Prefer learning as a group about diabetes care } \\
\text { Enjoy sharing experiences with peers }\end{array}$ \\
\hline Insurance makes a difference & $\begin{array}{l}\text { Feel unable to manage diabetes properly due to lack of insurance and } \\
\text { extremely high cost of care } \\
\text { Do not have access to health talks due to disconnection from health insurance } \\
\text { networks }\end{array}$ \\
\hline Transportation issues & $\begin{array}{l}\text { Consider transportation as a challenge, and this restricts the access of health } \\
\text { information } \\
\text { Affect willingness and ability to attend health talks }\end{array}$ \\
\hline $\begin{array}{l}\text { Limited information in the } \\
\text { Chinese-speaking community }\end{array}$ & $\begin{array}{l}\text { Acknowledge limitations due to poor English proficiency, continue to access } \\
\text { health information in Chinese } \\
\text { Consider translations to be not help much if cultural practices have not been } \\
\text { addressed }\end{array}$ \\
\hline \multicolumn{2}{|r|}{ - } \\
\hline Unawareness of self-care responsibility & $\begin{array}{l}\text { Do not think patients should take up responsibilities in chronic illness } \\
\text { management } \\
\text { Follow physician prescriptions with no knowledge of medications being taken }\end{array}$ \\
\hline Age related limitations & $\begin{array}{l}\text { - Admit limitations due to age related changes } \\
\text { - Acknowledge short attention span in reading or attending health talks }\end{array}$ \\
\hline
\end{tabular}

I will follow whatever the doctor tells me. It would be strange if the doctor discusses the treatment plan with me, and it is unnecessary for the doctor to do that. I have never accused the doctor for anything wrong. Just like a child and his father-the doctor is like our parent, and whatever he says is correct. If ... the doctor has said something wrong, and I notice it ... then I know more than the doctor. That's impossible! (Participant 16, male)

The strong sense of respect for doctors seemed to hinder the development of Chinese immigrants' capacity to obtain additional information about their treatment regime (HL1), communicate their needs and preferences with professionals (HL2), and process information about treatment plans (HL3).

\section{Desire to avoid being burdensome to others}

Participants stated that they tried to avoid burdening people around them, especially their families. Most of the participants shared common experiences. Some felt uncomfortable affecting the dietary habits of their family members. They believed that low-sugar and low-fat diets for people with diabetes were neither appetising nor of high quality. Therefore, they did not want their family members to suffer because of their own dietary restrictions. "I do not want the whole family to have less tasty food. ... Shanghai people like sweet stuff.
I do not want to ask them to put less sugar [in the food]" (Participant 16, male).

Most of the participants also stated they felt embarrassed about taking time and energy away from healthcare providers to address their health concerns. They considered the key responsibility of physicians and nurses to be curing or treating diseases. They did not expect physicians and nurses to take an active role in health education via discussions. Many of the participants felt it was impractical for nurses to provide extra services, such as conducting patient support groups, during non-office hours. The participants stated that health professionals were busy enough and they did not want to bother them.

Because the nurses should have the weekends off. ... It is impossible for the clinic to provide us with nurse-led support groups in a frequent manner, such as weekly or monthly. In fact, there is an alternative way to do this: all of us can exchange our phone numbers and we will contact with each other if we have time. (Participant 18, male)

The desire to avoid being burdensome to others seemed to affect Chinese immigrants' capacity to communicate their need for diet control to their family members (HL2). Dietary advice regarding reduced 
consumption of carbohydrates was perceived as a source of suffering for family members. Concern for others seemed to outweigh the benefits of dietary control and its possible effect on good health. On the other hand, some participants were hesitant to indicate their need for health education from healthcare professionals due to the concern of wasting professionals' time. Such perceptions may lower their capacity to communicate with healthcare professionals (HL2).

\section{Desire to be together or follow a collective approach}

Most of the participants reported that they enjoyed obtaining and exchanging diabetes information and thoughts with peers during the learning process. They felt that studying on their own was not interesting enough to maintain momentum. They preferred to discuss and consult with someone while they were learning. Most of the participants reported that they enjoyed a supportive atmosphere when learning and that group education was their accustomed learning style since childhood. Most of them highly valued the experiences of their peers and were willing to learn from one another. For example, one participant stated, "I enjoy learning together; it is so boring and not easy to learn by oneself. We can discuss together, exchange our experiences. [I] don't know what can be done by one person" (Participant 9, female).

Although I prefer to exchange ideas with others, I do not have opportunities to do so. My brother's [referring to another participant] experience must be different from mine, as our age is different. My brother must be very experienced in what he has been practicing in diabetes care. Also, I am good at what I have been paying attention to. Therefore, it is beneficial for us to exchange our ideas. (Participant 7, male)

The desire to be together seemed to affect the capacity of Chinese immigrants in this study to obtain health information (HL1) and communicate their preferences with peers (HL2). Favourable settings, such as a room for group discussion, may enhance the ability of Chinese immigrants to obtain health information and communicate with peers.

\section{Insurance makes a difference}

Many participants younger than 65 years did not have health insurance, whereas most of the participants 65 years or older reported having Medicaid and Medicare, the health insurance programmes provided by the state and federal governments. Most participants younger than 65 had jobs but did not receive health insurance from their employers. Due to low wages, they could not afford private health insurance. Participants who were employed said they cherished their jobs and did not want to lose them, even though health insurance was not offered. Many of them described longing to become older and looking forward to receiving health insurance in old age. Many also said they believe that by that age, their chronic illness could be handled properly. There were also reports of attending medical consultations without insurance and being shocked by the extremely high cost.

There is no way to ask for help. I cannot afford to visit doctors because I do not have health insurance. When I was first diagnosed with diabetes, the cost of diabetes medication was one dollar per pill, which was extremely high. [And I] need to take several pills per day. (Participant 13, male)

Many participants also received limited health information because they did not belong to an insurance network. They reported that their friends who had health insurance had many opportunities to receive health information, such as health talks held by their health insurance network or clinics. "I know there are some health talks organised by insurance networks. But I am not connected to any of these networks, so I received limited information" (Participant 2, female).

Insurance seemed to affect Chinese immigrants' access to health information (HL1).

\section{Transportation issues}

Many participants, especially women, said transportation was a challenge to accessing health information in Los Angeles (HL1). For example, they had difficulty reaching health centres to attend health talks. Some participants reported several reasons for not driving, such as poor eyesight or limited driving skills. Some indicated that taking public transportation in Los Angeles could be inconvenient. One participant stated that she used to faint in the street due to low blood glucose, which made her family members worry about her safety when she went out by herself. Most female participants relied on their spouses or children to take them out, which restricted their activities. When asked about the preferred venue for health talks, most participants stated 'the closer the better' or within walking distance.

My blood glucose goes up and down, which is unstable. My daughter keeps calling me and wants to pick me up because I fainted on the street twice. I told her that I would be going home by public transportation. She was still worried and asked me to be careful. (Participant 21, female)

Participants aged 65 or older reported relatively fewer transportation problems because their transportation was usually supported by non-governmental organisations or volunteers. However, it was still a challenge for them to travel to locations beyond their own neighbourhood. They also indicated they preferred health talks to be held within walking distance of their homes.

The capacity to travel independently and safely in the county seemed to be a crucial determinant affecting Chinese immigrants' access to health information (HL1). 
Limited information in the Chinese-speaking community

Most participants stated that they received less health information now (HL1) than when they were in China because they were not proficient in English. Many of these participants were still getting health information from the media in Chinese, by watching Chinese television programmes or browsing websites developed by people in China. However, many participants could not apply what they learned from these media because they did not find it to be consistent with practices in the USA. For example, some participants reported they learned that blood glucose levels should be in the range of 4-7 according to Chinese sources, whereas practitioners in the USA recommend a range of 100-140. Such discrepancies result from the use of different scales, and participants found it hard to adapt and adjust their interpretations of the figures. This example indicates how limited information in the Chinese-speaking community affects Chinese immigrants' capacity to process the meaning of health information (HL3). Some participants were not able to ask questions after watching Chinese television programmes (HL2) due to the geographic and time differences between the participants and the programme producers. Thus, this practice did not support the development of capacity to communicate the need for information (HL2).

Participants often reported being unsatisfied with the translation of health education materials in the USA. They commented that many translated materials were directly translated with limited concern about cultural contexts or usual practices in Chinese populations. They said they found the information irrelevant to their diabetic care practices. For example, participants found it hard to understand the information in food exchange charts and make choices because most of the suggested food, such as pizza and baked beans, is not common to the Chinese diet (HL4). Neglecting the sensitivity of cultural and/or usual practices in daily lives seemed to be the fundamental reason for the failure to support Chinese immigrants in processing the information (HL3) and understanding the choices and context of the information (HL4). "Although I am in America, I still look for things [health information] from China. That stuff [health information] works for me better" (Participant 16, male).

Public education on diabetes is limited in the Chinesespeaking community. There are many English-speaking programs; however, these programs do not suit us. These programs can be costly. Although United States has good welfare, it is still limited in this area. It is impossible for health professionals to reach out to every household. (Participant 8, male)

Limited information in the Chinese-speaking community affected Chinese immigrants' capacity to obtain and process health information (HL1) and hindered their desire to communicate health information with healthcare professionals (HL2), process the meaning of information (HL3) and understand choices regarding food (HL4).

\section{Unawareness of self-care responsibility}

Although some participants sought health information after being diagnosed with diabetes, a considerable number of participants reported that they were not active in self-care. Many of them did not become accustomed to looking for health information independently (HL1) and thus were unaware of the resources available in the community. Their belief was that they should not be responsible for chronic illness care. Some participants considered it to be the duty of others to invite them to attend health talks. "Nobody tells me. If I were told, I will go" (Participant 20, male). This may indicate a limited capacity to communicate their learning needs to healthcare professionals (HL2). In addition, a considerable number of participants also reported that they had no knowledge of what medications they were taking and would rather accept doctors' prescriptions without any discussion. Some participants reported they did not keep any records of medications they were taking or blood glucose self-monitoring.

When I first started taking medication, I didn't keep a recording of my blood glucose. I don't know what is high, what is low and what is normal. I only know that the doctor told me I have diabetes. I don't take care of the illness in a special manner. I think, I am just the way I am, nothing serious will happen, I eat whatever doctors give me. I don't have any special channel [to get health care information]. ... I trust doctors a lot, whatever they say I will follow. To be honest, I have no idea about what medications I am currently taking. (Participant 19, male)

Reporting a belief that patients should not be responsible for chronic illness care, Chinese immigrants did not seem to know that they should take initiatives and responsibilities for health maintenance; therefore they chose to assume a passive role in seeking health information (HL1). This perception may also affect their capacity to communicate with others (HL2). When they were asked to understand the choice of treatment options, Chinese immigrants said they were inclined to give up their rights and leave the decision to health professionals. Thus, their capacity to understand the choices and context of treatment (HL4) seemed to be underdeveloped.

\section{Age related limitations}

Older participants encountered limitations due to age related changes, such as vision and hearing problems and pain. They admitted they could not attend health talks for more than half an hour, otherwise they would experience back pain. Hearing problems were also common in this population; they struggled to hear the speakers clearly. They also had difficulty reading pamphlets or websites if the text of these printed or online materials was small. 
We are old now, sometimes we are forgetful. I do not want anything [health education]. I used to learn how to use a computer. When I learnt it, my eyes were not capable, my lower back was not capable. I cannot sit for a long time. So I want the simplest [health information], I don't want those complicated things. (Participant 22, female)

Age related limitations seemed to affect the frequency and duration of contacts with health professionals (HL2) and the mode of delivery of health information (eg, through printed text, verbal advice or online materials; HL1).

\section{DISCUSSION}

Chinese Americans, in particular those who are foreign born, have poor fluency in English or received little education, face major barriers to accessing and understanding diabetes related health information. ${ }^{4} 912$ Adding a new perspective to the examination of health literacy issues, the current study identified eight themes that are likely to be related to reasons why Chinese immigrants with type 2 diabetes had difficulty obtaining diabetes related information, processing the meaning and usefulness of the information, understanding the choices and context of the information, and communicating their needs and preferences to others. Figure 2 illustrates the possible relationships among these themes and health literacy.

As shown in the current study, language barriers may not be the only reason for their restricted ability to seek health information and their difficulty communicating with others and processing the received health messages. Their personal beliefs and concerns about others (cultural factors) made these first-generation Chinese immigrants diagnosed with diabetes hesitant to seek updated health information (HL1). As evidenced here, beliefs about the authoritative relationship between physicians and patients made it difficult for these Chinese immigrants to communicate their needs and preferences to others (HL2) and process the information (HL3).

High regard for authority has been noted in previous research as a paternalistic model of decision making regarding treatment, in which the patient assumes a passive, dependent role and the physician is the expert. ${ }^{15}$ In this paternalistic model, patient involvement is limited and physicians control information and treatment decisions; the patient simply complies with doctors' orders. ${ }^{15}$ Due to cultural influences, Chinese immigrants said they did not openly discuss their preferences with doctors (HL2). When they processed instructions (information) from doctors and had follow-up queries, they did not clarify with doctors. And when their diabetic care belief and/or practices were different from the doctor's advice, they tended to hide their true feelings and thoughts, and pretended to agree with the doctor's instructions during medical consultations. Consequently, their capacity to process the meaning and usefulness of information had never developed. Chinese immigrants' high regard for authority presents not only as obedience towards doctors but also as distrust and reluctance to receive services and diabetes related information from other health or related professionals. Thus, they had limited access to health education resources because they only trusted doctors and overlooked other available resources.

In addition, the current study showed that a desire to avoid being burdensome to others was primarily due to Chinese cultural norms that made participants refrain from seeking health information from healthcare professionals and clarifying their interpretations of health information (HL2). Furthermore, they felt that asking healthcare professionals to lead patient support groups was equivalent to placing a burden on these healthcare professionals. Chinese immigrants with diabetes held the view that the responsibility of doctors and nurses is
Figure 2 This diagram shows how study themes relate to different components of health literacy. Seven themes are related to the capacity to obtain health information. Six themes are related to the capacity to communicate needs and preferences to health care professionals or relatives. Two themes are related to the capacity to process the meaning of health information, and another two themes are related to the capacity to understand the choices, consequences and context of health information.

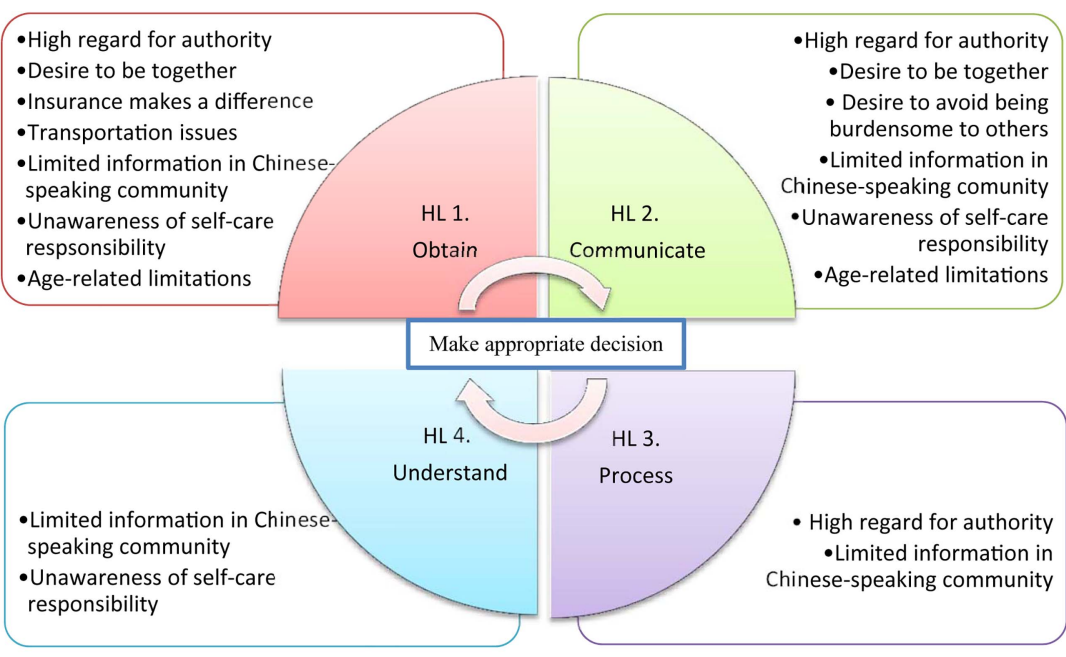

Note. $\mathrm{HL}=$ health literacy 
to cure rather than to educate; therefore, they were hesitant to ask doctors and nurses for health information during usual medical consultations (HL2). Thus, their health literacy, particularly their capacity to communicate with professionals (HL2), was limited by their unwillingness to consult with healthcare professionals. Many of them said they rely on lay sources of information, including friends and family, as key sources of advice regarding diabetes care. ${ }^{41}$ Moreover, efforts to avoid being burdensome to their family members made it difficult for participants to maintain a healthy routine, such as a special diet. This is an illustration of their limited ability to communicate their needs with family members (HL2).

Collectivism is one of the core elements of Chinese culture. ${ }^{16}$ To Chinese immigrants, peer learning experiences and group learning environments are crucial and lead to success. This finding is congruent with Lee $e t a l \mathrm{~s}$ study, ${ }^{16}$ in which collectivism was found to be related to physiological responses to stress among first-generation Chinese immigrants. Learning in a group is appealing to Chinese Americans not only because they can gain empirical self-management skills from others, but also due to their willingness to help peers by discussing their personal experiences. Previous research has also shown that culturally tailored support groups are effective in improving diabetes self-management skills among Chinese Americans. ${ }^{17}$ Due to smaller class sizes and the familiar cultural background of educators, the support group format allows participants to develop trust and rapport with educators and other group members and provides a safe environment for participants to share their feelings and thoughts. This use of group learning with Chinese immigrants for health education can enhance their willingness to receive health information (HL1).

In this study, we found that structural barriers are another potentially critical determinant of Chinese immigrants' health literacy (HL1, HL2, HL3 and HL4). Previous research has shown that low-wage Chinese immigrants usually experience a severe shortage in healthcare coverage and are forced to resort to several strategies to compensate for not having health insurance and access to healthcare facilities, including delaying medical care, using over-the-counter medicine and other remedies, and even returning to China for treatment. ${ }^{18}$ The current study contributed to the expansion of knowledge by showing the linkage between health insurance and individuals' capacity to obtain health information (HL1). Individuals with diabetes who do not have insurance have limited resources to obtain health information because they cannot attend health talks or health counselling sessions offered by insurance networks. Those who attend free clinics are reluctant to ask for more services beyond prescribed medications. From the perspective of these Chinese immigrants, requesting health talks or individual counselling sessions means placing a burden on healthcare professionals in these free clinics. Chinese patients with diabetes stated that healthcare professionals have already done enough to support patient care and it is not appropriate to ask them to offer more time or effort to conduct patient support groups. With the implementation of the Affordable Care Act, some of the issues in health insurance coverage among low-income or uninsured immigrants were addressed. ${ }^{19}$ For example, in California, the Cash Assistance Program for Immigrants is available for low-income immigrant seniors and immigrants with disabilities. ${ }^{20}$ Such new measures may increase Chinese Americans' access to healthcare but not necessarily change their ability to get relevant health information.

Transportation issues were found to be another structural barrier to accessing health information among Chinese immigrants (HL1). A majority of Chinese immigrants rely on public transportation rather than automobiles. Many of them were supported by family members in terms of transportation, thus restricting their ability to travel to places other than their own neighbourhood to get health information or attend health talks. Because of these limitations, healthcare professionals should consider organising health promotion activities in neighbourhoods populated by Chinese immigrants. Other innovative strategies for health promotion, such as approaches that capitalise on electronic and mobile technology, should be considered because they do not demand the physical presence of Chinese immigrants in a particular venue. Recent research found that 75 million adults in the USA used their smartphones for health information and tools. ${ }^{21}$ Among those aged 55 or older who own smartphones or tablets, half are using the devices for health purposes. ${ }^{21}$ Applications have been designed for clinical assessment, symptom monitoring, health education, resource location, treatment progress tracking, skills training and two-way communication with health providers. ${ }^{22}$

Limited diabetes education resources in Chinesespeaking communities in the USA undermine their impact on Chinese immigrants' capacity to obtain information (HL1), communicate health information with others (HL2), process the meaning of the information (HL3) and understand the choices and consequences of the information (HL4). Our findings echoed the results of previous studies that showed that Chinese immigrants found translated materials about diabetes to be culturally and linguistically inappropriate and did not provide enough details to be useful in their daily lives. ${ }^{23} 24$ Chinese immigrants had difficulty processing the information from education leaflets (HL3) and understanding choices in food exchanges (HL4). Despite frequent searching for diabetes healthcare resources in Chinese websites and Chinese media by these immigrants, many inconsistencies can be found between Chinese resources and daily healthcare practices in the USA, leading to more confusion in terms of processing the meaning of information (HL3) and understanding the information (HL4). Potential strategies for healthcare professionals in the USA to support these Chinese immigrants 
include narrowing the gap between disseminated health messages (which can be from different and even international sources) and clinical practices. A deeper understanding of the beliefs of Chinese immigrants and barriers to health information seeking behaviour is needed. ${ }^{25}$

Chinese immigrants with diabetes also experienced various personal barriers. Age related changes led to certain limitations cited by older Chinese immigrants. Many of these older immigrants had difficulty attending health talks due to hearing loss, pain, inability to focus for long periods and vision problems. These age related limitations may hinder their capacity to obtain health information (HL1) and communicate their need for information (HL2). Thus, more flexible learning models, such as short lectures with longer breaks, may be more appropriate for these older Chinese immigrants. Another possible strategy is the use of family based interventions in which spouses or adult children are involved as lay health educators and become responsible for disseminating and interpreting relevant health information. ${ }^{26}$

Unawareness of self-care responsibilities or passive health related learning styles was evidenced among the first-generation Chinese immigrants in this study. The reluctance to assume responsibility for self-care affected various components of health literacy. First, they were passive towards seeking health information (HL1). Second, they considered giving information to patients as healthcare professionals' responsibility and initiatives. They seemed unprepared to tell healthcare professionals about their learning needs (HL2). Third, they did not appear to have a desire to understand the treatment regime and options (HL4). This behaviour is contradictory to practices in the current US healthcare system, which requires active participation by patients. ${ }^{26}$ Training should be provided to encourage Chinese immigrants to take responsibility for their own health and become active participants in chronic illness management. ${ }^{27}$

This study attempts to explore factors that might contribute to health literacy in the Chinese population. These study results provide meaningful implications regarding service needs. First, it is critical for health providers to use a culturally sensitive approach when working with Chinese immigrants with diabetes. It is important for practitioners to understand the cultural norms embraced by Chinese immigrants, such as their high regard for authority and desire to avoid being burdensome to others. It is essential for health professionals to encourage their patients to make healthcare related choices and empower their autonomy in treatment decision making. Local community centres or adult day-care centres could organise support groups for Chinese immigrants with diabetes to address their desire to learn together and their limitations related to transportation. In addition, health providers need to take the physical conditions of older patients into consideration when forming health education plans. Health education services should be tailored for specific age groups such as retired older adults and working adults. Researchers and practitioners in the field of diabetes education also need to understand the diversity of Chinese immigrants within and across ethnic groups when developing social services and conducting research. Third, promoting and improving existing health education services is needed in conjunction with developing new programmes. Access to public health education services can be enhanced by providing language support via translation services offered by Chinese-speaking health professionals. ${ }^{23}$ In current practice, services being provided to Chinese American immigrants with no insurance are limited to physicians' diagnosis, regular medical consultations and drug prescriptions, which are often provided by charity organisations or religious groups. Due to the shortage of resources in these charity organisations, services related to preventive education (such as health talks regarding prediabetes) and self-care management (such as blood glucose self-monitoring) are scarce or non-existent. Thus, there is plenty of room for improvement in diabetes education and care for Chinese American immigrants, considering the cultural, structural and personal factors affecting their health literacy.

The findings of the current study echoed previous studies in which similar barriers, such as a lack of health insurance, negatively affected Korean immigrants' ability to obtain diabetes preventive care and health information. ${ }^{28}$ Asian immigrants were also found to be disadvantaged in terms of obtaining healthcare due to linguistic barriers, cultural incompetence regarding American health systems, lack of insurance and being discriminated against in the healthcare system. ${ }^{29}$ Thus, the findings of the current study may not only be restricted to Chinese American immigrants but may also extend to other ethnic groups.

This study had several limitations. First, it was limited in its methodology as a qualitative study with purposive sampling. The sample was recruited from retirement communities and free clinics. Thus, this sample represented older adults who lived in subsidised housing or middle-aged immigrants who had low income or no health insurance. Therefore, the study findings cannot be generalised to all Chinese Americans with type 2 diabetes. Although the results of this study cannot be generalised to a larger population due to design limitations, research has shown that similar barriers such as low health literacy, linguistic issues and lack of insurance negatively affect Korean immigrants with type 2 diabetes in terms of obtaining preventive care and health information. ${ }^{28}$ Second, it was observed that the percentage of male participants in the current study was much higher than the female counterparts $(62 \%$ and $38 \%$, respectively). This phenomenon may be due to the fact that many female immigrants had to rely on transportation support from family members; thus they were not able to join the study despite being invited. This sample may not be generalised to the immigrant population in California, as the ratio of male to female immigrants in 2010 and 2011 was almost $1: 1 .^{30}$ 
Third, it should also be acknowledged that personal barriers to accessing health information may vary among individuals. Some personal barriers (financial status, employment status, housing environment, etc.) were not investigated in this study. Thus, future research should further investigate these personal factors that may influence health literacy. Finally, the health literacy of participants in this study was not assessed. Therefore, it is uncertain whether participants had varying levels of health literacy. A tool should be developed to measure health literacy among minorities. The commonly used functional health literacy scales, such as the Test of Functional Health Literacy in Adults (TOFHLA) or the Rapid Estimate of Adult Literacy in Medicine (REALM), have been criticised for their limitations in the scope of measurement, which restrict the measures to functional health literacy only. Health literacy is a broad concept with multiple dimensions. Thus, measuring one dimension of health literacy (functional health literacy only) may not be appropriate. Using the framework as shown in figure 1 and making reference to CDC's definition of health literacy, we propose to develop a health literacy scale using a 5-point Likert scale (1=strongly disagree and $5=$ strongly agree). Examples of item in this new health literacy scale are: (1) I feel unease asking healthcare professional questions; (2) I cannot get health information because no one helps me; (3) I seldom attend health talks because I am not invited; (4) I seldom attend health talks because no one offers me a free ride; and (5) I cannot obtain health information because the materials cannot be applied to my daily healthcare practice. The current study has provided groundwork for future research in health literacy issues in non-English-speaking populations in the USA. Research in this area deserves attention and support.

Acknowledgements We wish to acknowledge the invaluable contribution of the study participants. Special thanks go to Debra Boudreaux, Rosanna Che, Tongxin Cui, Audrey Hai, Sanford Guan, Chang Liu and Bernabeth Sy for their kind support and assistance during data collection and the anonymous reviewers for their thoughtful review and guidance. We would also like to thank Golden Age Village, Herald Christian Health Center and Tzu Chi Health Centre for their kind support during data collection.

Contributors AYML contributed to the study design, application for ethical approval, funding application, data analysis, interpretation of the findings and revision of the manuscript. $A B$ contributed to data collection, data analysis and drafting of the manuscript. $\mathrm{H}-\mathrm{YH}$ contributed to data collection and data analysis. SSW contributed to data collection and data analysis. IC contributed to study design, funding application, data analysis, interpretation of the findings and revision of the manuscript.

Funding This project was funded by the HKU Overseas Fellowship Award 2013-2014 from the University of Hong Kong (project number: 102009239), the HKU/China Medical Board Grants 2011/2012 from the University of Hong Kong and the USC Edward R. Roybal Institute on Aging at the University of Southern California.

Competing interests None.

Patient consent Obtained.

Ethics approval Approval was obtained from the Ethical Review Board of the University of Hong Kong/Hospital Authority Hong Kong West Cluster (IRB reference no: UW13-514).
Provenance and peer review Not commissioned; externally peer reviewed.

Data sharing statement Extra data can be accessed via the Dryad data repository at http://datadryad.org/ with the doi:10.5061/dryad.1pj40.

Open Access This is an Open Access article distributed in accordance with the Creative Commons Attribution Non Commercial (CC BY-NC 4.0) license, which permits others to distribute, remix, adapt, build upon this work noncommercially, and license their derivative works on different terms, provided the original work is properly cited and the use is non-commercial. See: http:// creativecommons.org/licenses/by-nc/4.0/

\section{REFERENCES}

1. Centers for Disease Control and Prevention. Prevalence and trends: California-2010: diabetes. Atlanta, GA: Surveillance, Epidemiology, and Laboratory Services Office, 2011.

2. Lee JWR, Brancati FL, Yeh HC. Trends in the prevalence of type 2 diabetes in Asians versus Whites: results from the United States National Health Interview Survey, 1997-2008. Diabetes Care 2011;34:353-7.

3. Kim G, Ford KL, Chiriboga DA, et al. Racial and ethnic disparities in healthcare use, delayed care, and management of diabetes mellitus in older adults in California. J Am Geriatr Soc 2012;60:2319-25.

4. King GL, McNeely MJ, Thorpe LE, et al. Understanding and addressing unique needs of diabetes in Asian Americans, native Hawaiians, and Pacific Islanders. Diabetes Care 2012;35:1181-8.

5. Centers for Disease Control and Prevention. Learn about health literacy. http://www.cdc.gov/healthliteracy/Learn/

6. Berkman ND, Davis TC, McCormack L. Health literacy: what is it? $J$ Health Commun 2010;15:9-19.

7. Gucciardi E, Smith PL, DeMelo M. Use of diabetes resources in adults attending a self-management education program. Patient Educ Couns 2006;64:322-30.

8. Kreps GL, Sparks L. Meeting the health literacy needs of immigrant populations. Patient Educ Couns 2008;71:328-32.

9. Chesla CA, Chun KM. Accommodating type 2 diabetes in the Chinese American family. Qual Health Res 2005;15:240-55.

10. Fisher L, Skaff MM, Chesla CA, et al. Disease management advice provided to African-American and Chinese-American patients with type 2 diabetes. Diabetes Care 2004;27:2249-50.

11. Kwan CM, Chun KM, Chesla CA. Cultural norms shaping research group interviews with Chinese American immigrants. Asian Am J Psychol 2011;2:115-27.

12. Maxwell JA. Qualitative research design: an interactive approach. Thousand Oaks, CA: Sage, 1996.

13. McGartland Rubio D, Berg-Weger M, Tebb SS, et al. Objectifying content validity: conducting a content validity study in social work research. Soc Work Res 2003;27:94-104.

14. Wang JHY, Adams IF, Pasick RJ, et al. Perceptions, expectations, and attitudes about communication with physicians among Chinese American and non-Hispanic White women with early stage breast cancer. Support Care Cancer 2013;21:3315-25.

15. Tariman JD, Berry DL, Cochrane B, et al. Physician, patient, and contextual factors affecting treatment decisions in older adults with cancer and models of decision making: a literature review. Oncol Nurs Forum 2012;39:E70-83.

16. Lee YSC, Suchday S, Wylie-Rosett J. Social support and networks: cardiovascular responses following recall on immigration stress among Chinese Americans. J Immigr Minor Health Published Online First: 28 November 2013. doi:10.1007/s10903-013-9955-9

17. Sun AC, Tsoh JY, Saw A, et al. Effectiveness of a culturally tailored diabetes self-management program for Chinese Americans. Diabetes Educ 2012;38:685-94.

18. Pih $\mathrm{KKH}$, Hirose A, Mao KR. The invisible unattended: low-wage Chinese immigrant workers, health care, and social capital in Southern California's San Gabriel Valley. Sociol Inq 2012;82:236-56.

19. The U.S. Centers for Medicare and Medicaid Services. Health Insurance Marketplace. https://www.healthcare.gov/ (accessed 27 Jun 2014).

20. National Immigration Law Centre (NILC). Programs for immigrants in California. http://www.nilc.org/benefitsca.html (accessed 27 Jun 2014).

21. Dolan B. Twice as many use tablets for health tools, information. MobiHealthNews 2012.

22. Luxton DD, McCann RA, Bush NE, et al. mHealth for mental health: integrating smartphone technology in behavioral healthcare. Prof Psychol Res Pr 2011;42:505-12. 
23. Chen CJ, Kendall J, Shyu YIL. Grabbing the rice straw: health information seeking in Chinese immigrants in the United States. Clin Nurs Res 2010;19:335-3.

24. Ho EY, Chesla CA, Chun KM. Health communication with Chinese Americans about type 2 diabetes. Diabetes Educ 2012;38:67-76.

25. Ton TGN, Steinman L, Yip MP, et al. Knowledge of cardiovascular health among Chinese, Korean and Vietnamese immigrants to the US. J Immigr Minor Health 2011;13:127-39.

26. Lee JS. Channels of health communications used among Korean and Asian Indian older adults. Soc Work Health Care 2010;49:165-75.
27. van den Arend IJM, Stolk RP, Krans HMJ, et al. Management of type 2 diabetes: a challenge for patient and physician. Patient Educ Couns 2000;40:187-94.

28. Choi SE, Rush E, Henry S. Health literacy in Korean immigrants at risk for type 2 diabetes. J Immigr Minor Health 2013;15:553-9.

29. Juliana C, Sunmin L, Chae DH. Barriers to health care among Asian immigrants in the United States: a traditional review. J Health Care Poor Underserved 2013;24:384-403.

30. UCLA Centre for Health Policy Research. California Health Interview Survey. http://healthpolicy.ucla.edu/chis/data/Pages/overview.aspx (accessed 27 June 2014). 